\title{
Repeated triplets complicated by monochorionic diamniotic twins following assisted reproduction: a case report and literature review
}

Bing Song ${ }^{1,2,3,4,5}$, Zhe Wang ${ }^{1}$, Yujie Chen ${ }^{1}$, Chao Wang ${ }^{1,2,3,4,5}$, Zhaolian Wei ${ }^{1,2,3,4,5}$, Xiaojin He ${ }^{1,2,3,4,5^{*}}$ and Yunxia Cao ${ }^{1,2,3,4,5^{*}}$

\begin{abstract}
Background: Monochorionic twinning involves numerous maternal and fetal complications, triplets complicated by a monochorionic pair are at further increased risk. Here, we report a case of repeated triplets complicated by monochorionic diamniotic twins with successful pregnancy outcomes in a woman using autologous oocytes.

Case presentation: A 30-year-old female undergoing embryo transfer with fresh and frozen embryo cycles with autologous oocytes. The two cycles were confirmed by transvaginal ultrasound to result in successful clinical pregnancies of triplets complicated by a monochorionic twinning. The first pregnancy resulted in a singleton delivery after a selective reduction of the monochorionic pair. The subsequent pregnancy resulted in a dichorionic diamniotic twin pregnancy after the heartbeat of one of the monochorionic twin fetuses stopped at 43 days after embryo transfer. Both of the pregnancies ended with successful live births.

Conclusions: Our case report of repeated triplets with monochorionic twins suggests the potential causes and risk factors of monochorionic twinning in assisted reproduction and raises concern regarding the timing of multifetal pregnancy reduction.
\end{abstract}

Keywords: Triplets, Monochorionic diamniotic twins, Assisted reproduction, Case report

\section{Background}

Many studies have demonstrated that an increased risk of monozygotic twins(MZT) was associated with assisted reproductive techniques(ART) procedures [1-4]. According to published studies, the incidence of MZT after ART varies from 1.57 to $13.2 \%$ compared with the natural conception rate of $0.4 \%$ [1-5]. There are three types of monozygotic: dichorionic-diamniotic, monochorionicdiamniotic and monochorionic-monoamniotic.

* Correspondence: hxj0117@126.com; caoyunxia6@126.com

${ }^{1}$ Reproductive Medicine Center, Department of Obstetrics and Gynecology, the First Affiliated Hospital of Anhui Medical University, Hefei 230032, China Full list of author information is available at the end of the article
Monochorionic twin occupies most of the proportion of the incidence in monozygotic twinning. It is well-known that monochorionic twins are at high risk of maternal and fetal complications, including low birthweight, preterm birth, twin-twin transfusion syndrome(TTTS), umbilical cord accidents and perinatal mortality [6-9]. Regarding dichorionic triplets pregnancy, the rate was only $0.004 \%$ among all the pregnancies, as previously reported [10]. Here, we describe a rare case of repeated triplet pregnancy complicated by a monochorionic diamniotic twin in a patient after assisted reproduction. To the best of our knowledge, this is the first published

(c) The Author(s). 2020 Open Access This article is licensed under a Creative Commons Attribution 4.0 International License, which permits use, sharing, adaptation, distribution and reproduction in any medium or format, as long as you give appropriate credit to the original author(s) and the source, provide a link to the Creative Commons licence, and indicate if changes were made. The images or other third party material in this article are included in the article's Creative Commons licence, unless indicated otherwise in a credit line to the material. If material is not included in the article's Creative Commons licence and your intended use is not permitted by statutory regulation or exceeds the permitted use, you will need to obtain permission directly from the copyright holder. To view a copy of this licence, visit http://creativecommons.org/licenses/by/4.0/. The Creative Commons Public Domain Dedication waiver (http://creativecommons.org/publicdomain/zero/1.0/) applies to the data made available in this article, unless otherwise stated in a credit line to the data. 
report of this kind. This case highlights the risk factors and obstetric outcomes of dichorionic triplets.

\section{Case presentation}

A couple who complained of secondary infertility for 6 years underwent IVF treatment due to polycystic ovarian syndrome and male ejaculatory dysfunction. The patient was a 30-year-old female, her cycle was followed with a standard long protocol for 18 days that included uFSH (150 units every day, Zhuhai, China) and HMG (75 units every day after 8th day of ovarian stimulation; Zhuhai, China). Final oocyte maturation was triggered by the administration of 10,000 IU of HCG (HCG $10000 \mathrm{U}$ for injection; Zhuhai, China). Oocyte retrieval was carried out by the transvaginal ultrasound-guided puncture of follicles. Sixteen mature oocytes were retrieved under transvaginal ultrasound guidance, of which 13 were fertilized after intracytoplasmic sperm injection(ICSI). Finally, 7 good-quality embryos were retrieved. Embryo culture in vitro showed two 8-cell embryos (grade A) and two 9cell embryos (grade B) on day 3. Other embryos were culture to day 5 and yielded 3 viable blastocysts.

Two cleavage embryos (one 8-cell embryo and one 9cell embryo) were transferred on day 3 in the fresh cycle. The other two day 3 embryos were cryopreserved. Luteal progesterone support was given after the oocyte operation. The patient had confirmed pregnancy by a urine pregnancy test on day 14 post-transfer. Dichorionic triplets were diagnosed by a transvaginal ultrasound scan at 5 weeks post-transfer, as two gestational sacs (GSs) inside the uterus and two pulsating echoes were detected in one of the GS (Fig. 1A). After counselling the maternal and fetal risks, the patient decided to have a single pregnancy with the help of multifetal pregnancy reduction(MFPR) for both monochorionic twins. The selective MFPR was successfully performed at 6 weeks posttransfer. The subsequent pregnancy went well without any complications. The patient had a full-term vaginal delivery at 41 weeks and 6 days. The birth weight and Apgar scores at $1 \mathrm{~min}$ and $5 \mathrm{~min}$ were $3800 \mathrm{~g}$ and 10 10.respectively.

When China's two-child policy was loosened, the patient requested a frozen embryo transfer when she was 33 years old. Hormone replacement therapy (HRT) was used in the first frozen cycle. A single blastocyst (Gardner's classification: 4AA) was transferred, and the transfer failed. During the next cycle, two day 6 embryos (Gardner's classification: 4CB*2) was transferred, but the transfer failed again. The woman successfully conceived in the following cycle after two cleavage embryos (8 cells grade 2 and 9 cells grade 2) were transferred. We first suspected dizygotic twins, as two gestational sacs (GSs) was detected with transvaginal US on day 30 posttransfer. However, the US showed two GSs with three fetuses one week later, and another dichorionic triamniotic triplet pregnancy was suspected (Fig. 1B). The heartbeat of one of the monozygotic twins stopped suddenly on day 43 post-transfer, resulting in a dichorionic diamniotic twin pregnancy. Two healthy boys were delivered by emergency caesarean section at 35 weeks and 2 days of gestation due to premature rupture of membrane (PROM). Their birth weight and Apgar scores at $1 \mathrm{~min}$ and $5 \mathrm{~min}$ were $1900 \mathrm{~g}, 9-10$ and $2800 \mathrm{~g}, 10-10$, respectively. The lighter baby was sent to the neonatal care unit and was discharged 3 weeks after birth.

\section{Discussion and conclusions}

The data showed that there may be a significantly elevated risk of monozygotic twins after ART compared to natural conception [2,3]. Monochorionic twin occupies most of the proportion of the incidence in monozygotic twinning. According to our previous large retrospective cohort study, the overall incidence of monochorionic diamniotic twinning was $2.55 \%$ after ART [4]. It was
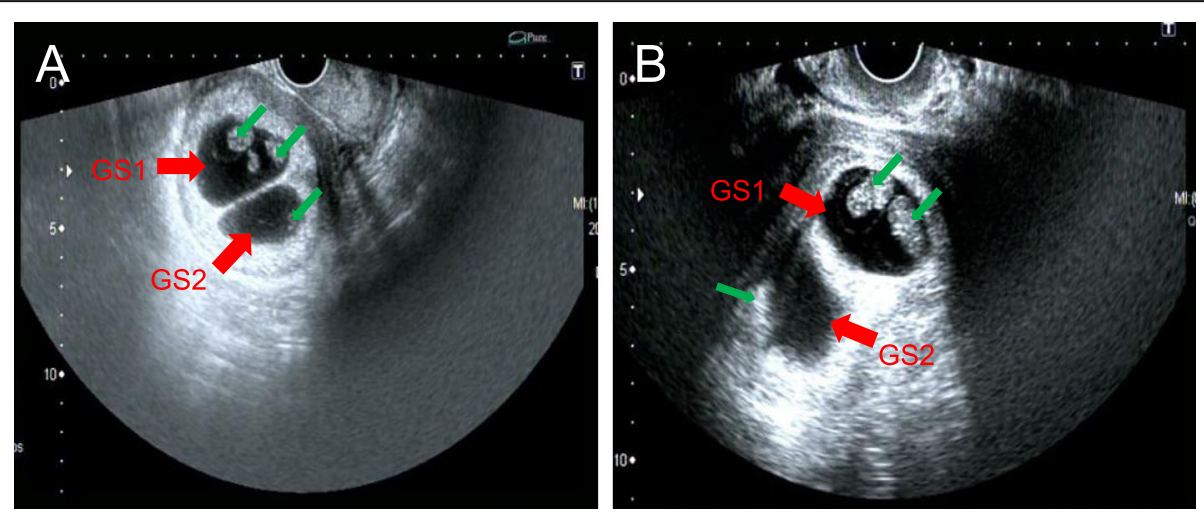

Fig. 1 Dichorionic triplets were diagnosed by transvaginal ultrasound, two gestational sacs (GSs, red arrowhead) and three germs (green arrowhead) were detected inside the uterus. A) Ultrasound image of first pregnancy at 5 weeks post-transfer. B) Ultrasound image of second pregnancy on day 37 post-transfer 
difficult to identify the exact mechanisms responsible for embryonic splitting after ART [11]. Potential risk factors that lead to an increased incidence may be micromanipulation of the zona pellucida(ZP), blastocyst transfer, age of the oocyte, and embryo cohort quality. The cause has been investigated but is still controversial [12-23].

It is plausible that an artificial breach in the $\mathrm{ZP}$ caused by the ICSI, assisted hatching $(\mathrm{AH})$ or preimplantation genetic diagnosis may cause splitting of the inner cell mass(ICM) and MZ twinning [15, 16]. However, recent studies have questioned the role of ZP manipulation, because these studies did not find an increased rate of MZT after the ICSI and AH [17]. Many studies have examined maternal age (or oocyte age) as a risk factor. Song et al. and Knopman et al. both observed a significant increase in the rate of MZT with younger maternal age and proposed that the age of the oocyte could be an important contributor to the incidence of MZT [4, 12]. This conclusion was confirmed in a systematic metaanalysis [13].

Recent studies reported that the transfer of a blastocyst resulted in a higher incidence of $\mathrm{MZ}$ pregnancies than the transfer of cleavage-stage embryos [18-22]. Our 6-year single center retrospective study demonstrated that younger maternal age and prolonged embryo culture might be potential contributing factors associated with a higher incidence of monochorionic diamniotic twinning in ART [4]. However, some researchers attributed this association to the high-quality embryos generated by prolonged embryo culture. In their opinion, blastocyst transfer is not associated with the incidence of MZT when controlling for embryo cohort quality [23].

It has been shown that multiple pregnancies are associated with an increased incidence of abortion and premature labor. Triplets complicated by a monochorionic twin are at further increased risk of many maternal and fetal complications [24]. A selective reduction of the monochorionic pair is usually recommended when using MFPR in the obstetric management of complex triplets $[25,26]$. In the first pregnancy of this case, we had a good obstetric outcome (full-term normal delivery at 41 weeks +6 days in this case). The transvaginal fetal reduction technique proved to be safe and effective, and it can be performed as early as 7 weeks of gestation. However, it should be noted that spontaneous reduction can occur before 12 weeks, and some scholars propose that selective reduction should be performed between 10 and 13 weeks when the nuchal translucency((NT) thickness and fetal abnormalities are easier to measure and diagnose $[26,27]$. In the second successful pregnancy of the patient, the heartbeat in one of the monozygotic twin fetuses stopped at 43 days after embryo transfer, and the patient had a dichronic twin pregnancy. Guidelines or an expert consensus should be issued regarding the timing and decision to retain the singleton or twins when using MFPR in triplet pregnancies with monochorionic twins.

To our knowledge, this is the first reported case of repeated triplets complicated by a monochorionic pair in a patient with autologous oocytes following assisted reproduction treatment. Potential risk factors for this patient include young maternal age, high quality embryos and micromanipulation of the ZP. In the cases with dichorionic triplets, selective multifetal pregnancy reduction is associated with a better obstetric outcome and should be offered in the obstetric management. While these cases are no longer rare after an ART procedure, the potential causes and risk factors of monochorionic twinning in assisted reproduction and the timing of MFPR warrant continued investigation.

\section{Abbreviations \\ MZT: Monozygotic twins; ART: Assisted reproductive techniques; ICSI: Intracytoplasmic sperm injection; MFPR: Multifetal pregnancy reduction; ZP: Zona pellucida; HRT: Hormone replacement therapy; GSs: Gestational sacs; AH: Assisted hatching}

\section{Acknowledgements}

We would like to thank our patient for allowing us to publish her clinical data.

\section{Authors' contributions}

BS and ZW designed the report; YJC and CW collected the patient's clinical data; BS and ZLW analyzed the data and wrote the paper; $\mathrm{XH}$ and YXC finally reviewed the paper. All authors read and approved the final manuscript.

\section{Funding}

None.

Availability of data and materials

The data referred to this case during the current study was available on reasonable request.

Ethics approval and consent to participate

The study was approved by the Committee on Medical Ethics of the First Affiliated Hospital of Anhui Medical University.

Consent for publication

Written informed consent was obtained from the patient for publication of this case report.

\section{Competing interests}

The authors declare that they have no conflicts of interest.

\section{Author details}

${ }^{1}$ Reproductive Medicine Center, Department of Obstetrics and Gynecology, the First Affiliated Hospital of Anhui Medical University, Hefei 230032, China ${ }^{2} \mathrm{NHC}$ Key Laboratory of Study on Abnormal Gametes and Reproductive Tract, Anhui Medical University, Hefei 230032, China. ${ }^{3}$ Ministry of Education Key Laboratory of Population Health Across Life Cycle, Anhui Medical University, Hefei 230032, China. ${ }^{4}$ Anhui Province Key Laboratory of Reproductive Health and Genetics, Hefei 230032, China. ${ }^{5}$ Biopreservation and Artificial Organs, Anhui Provincial Engineering Research Center, Anhui Medical University, Hefei 230032, China. 
Received: 21 March 2020 Accepted: 12 June 2020

Published online: 23 June 2020

\section{References}

1. Sobek A, Prochazka M, Klaskova E, Lubusky M, Pilka R. High incidence of monozygotic twinning in infertility treatment. Biomed papers. 2016;160: 358-62.

2. Nakasuji T, Saito H, Araki R, Nakaza A, Nakashima A, Kuwahara A, Ishihara O, Irahara M, Kubota T, Yoshimura $Y$, et al. The incidence of monozygotic twinning in assisted reproductive technology: analysis based on results from the 2010 Japanese ART national registry. J Assist Reprod Genet. 2014 31:803-7.

3. Mateizel I, Santos-Ribeiro S, Done E, Van Landuyt L, Van de Velde H, Tournaye $H$, Verheyen G. Do ARTs affect the incidence of monozygotic twinning? Hum Reprod. 2016;31:2435-41.

4. Song B, Wei ZL, Xu XF, Wang X, He XJ, Wu H, Zhou P, Cao YX. Prevalence and risk factors of monochorionic diamniotic twinning after assisted reproduction: a six-year experience base on a large cohort of pregnancies. PLoS One. 2017;12:e0186813.

5. Aston Kl, Peterson CM, Carrell DT. Monozygotic twinning associated with assisted reproductive technologies: a review. Reproduction. 2008;136:37786.

6. Derom R, Bryan E, Derom C, Keith L, Vlietinck R. Twins, chorionicity and zygosity. Twin Res. 2001;4:134-6.

7. Carroll SG, Tyfield L, Reeve L, Porter H, Soothill P, Kyle PM. Is zygosity or chorionicity the main determinant of fetal outcome in twin pregnancies? Am J Obstet Gynecol. 2005;193:757-61.

8. Kontopoulos E, Chmait RH, Quintero RA. Twin-to-twin transfusion syndrome: definition, staging, and ultrasound assessment. Twin Res Hum Genet. 2016; 19:175-83.

9. Benirschke K. The monozygotic twinning process, the twin-twin transfusion syndrome and acardiac twins. Placenta. 2009;30:923-8.

10. Yanaihara A, Ohgi S, Motomura K, Taniguchi R, Hatakeyama S, Yanaihara T. Dichorionic triplets following frozen-thawed poor-stage embryo transfer: a report of two cases and a review. Reprod Biol Endocrinol. 2017;15:80.

11. Steinman G. Mechanisms of twinning. VI. Genetics and the etiology of monozygotic twinning in in vitro fertilization. J Reprod Med. 2003;48:58390.

12. Knopman J, Krey LC, Lee J, Fino ME, Novetsky AP, Noyes N. Monozygotic twinning: an eight-year experience at a large IVF center. Fertil Steril. 2010;94 502-10

13. Hviid KVR, Malchau SS, Pinborg A, Nielsen HS. Determinants of monozygotic twinning in ART: a systematic review and a meta-analysis. Hum Reprod Update. 2018.

14. Alikani M, Cekleniak NA, Walters E, Cohen J. Monozygotic twinning following assisted conception: an analysis of 81 consecutive cases. Hum Reprod. 2003;18:1937-43.

15. Sills ES, Moomjy M, Zaninovic N, Veeck LL, McGee M, Palermo GD, Rosenwaks Z. Human zona pellucida micromanipulation and monozygotic twinning frequency after IVF. Hum Reprod. 2000;15:890-5.

16. Tarlatzis BC, Qublan HS, Sanopoulou T, Zepiridis L, Grimbizis G, Bontis J. Increase in the monozygotic twinning rate after intracytoplasmic sperm injection and blastocyst stage embryo transfer. Fertil Steril. 2002;77:196-8.

17. Elizur SE, Levron J, Shrim A, Sivan E, Dor J, Shulman A. Monozygotic twinning is not associated with zona pellucida micromanipulation procedures but increases with high-order multiple pregnancies. Fertil Steril. 2004;82:500-1.

18. Wright V, Schieve LA, Vahratian A, Reynolds MA. Monozygotic twinning associated with day 5 embryo transfer in pregnancies conceived after IVF. Hum Reprod. 2004;19:1831-6.

19. Moayeri SE, Behr B, Lathi RB, Westphal LM, Milki AA. Risk of monozygotic twinning with blastocyst transfer decreases over time: an 8-year experience. Fertil Steril. 2007:87:1028-32.20

20. Roberts AD, Schmidt R, Shah M. Split happens: a case of consecutive monozygotic twin pregnancies following elective single-embryo transfer in a 40-year old woman using donor oocytes. J Assist Reprod Genet. 2018.

21. Luke B, Brown MB, Wantman E, Stern JE. Factors associated with monozygosity in assisted reproductive technology pregnancies and the risk of recurrence using linked cycles. Fertil Steril. 2014;101:683-9.
22. Knopman JM, Krey LC, Oh C, Lee J, McCaffrey C, Noyes N. What makes them split? Identifying risk factors that lead to monozygotic twins after in vitro fertilization. Fertil Steril. 2014;102:82-9.

23. Franasiak JM, Dondik Y, Molinaro TA, Hong KH, Forman EJ, Werner MD, Upham KM, Scott RT Jr. Blastocyst transfer is not associated with increased rates of monozygotic twins when controlling for embryo cohort quality. Fertil Steril. 2015;103:95-100

24. Sun L, Zou G, Zhou F, Yang Y, Oepkes D, Duan T. Outcome of dichorionic triamniotic triplet: the experience from an emerging fetal therapy center. J Matern Fetal Neonatal Med. 2017:1-5.

25. Li R, Chen X, Yang S, Yang R, Ma C, Liu P, Qiao J. Retain singleton or twins? Multifetal pregnancy reduction strategies in triplet pregnancies with monochorionic twins. Eur J Obstet Gynecol Reprod Biol. 2013;167:146-8.

26. Herranz G. The timing of monozygotic twinning: a criticism of the common model. Zygote. 2015;23:27-40.

27. Haas J, Barzilay E, Hourvitz A, Dor J, Lipitz S, Yinon Y, Shlomi M, Shulman A. Outcome of early versus late multifetal pregnancy reduction. Reprod BioMed Online. 2016;33:629-34.

\section{Publisher's Note}

Springer Nature remains neutral with regard to jurisdictional claims in published maps and institutional affiliations.
Ready to submit your research? Choose BMC and benefit from:

- fast, convenient online submission

- thorough peer review by experienced researchers in your field

- rapid publication on acceptance

- support for research data, including large and complex data types

- gold Open Access which fosters wider collaboration and increased citations

- maximum visibility for your research: over $100 \mathrm{M}$ website views per year

At BMC, research is always in progress.

Learn more biomedcentral.com/submissions 